\title{
A construção discursiva de Dilma Rousseff: análise \\ DA PRIMEIRA PÁGINA DE TRÊS JORNAIS MINEIROS À LUZ DOS ESTUDOS SISTÊMICO-FUNCIONAIS ${ }^{1}$
}

\section{(The discursive construction of Dilma Rousseff: a systemic functional analysis of three newspapers?)}

\author{
Maria Carmen Aires Gomes \\ (Universidade Federal de Viçosa (UFV) \\ Maíra Ferreira SANT'ANA \\ (Universidade Federal de Viçosa (UFV)
}

\begin{abstract}
This research analyzes the representation of Dilma Rousseff, in the front page of three Minas Newspapers, after the results of the 2010 elections - Estado de Minas, Hoje em Dia and Super Notícia -, based on Systemic-Functional Linguistics (Halliday (1994) and Halliday e Matthiessen (2004)). Our objective is to understand the ideology underlying the picture construed of the social actor candidate for the presidency. The picture of Dilma Rousseff painted revealed the ideology of the owner - editor - of each newspaper revealed representing the social actor Dilma Rousseff president on your way.
\end{abstract}

Key-words: systemic-functional linguistics, social actor, society, context.

Resumo: Esta pesquisa analisou a representação da presidente Dilma Rousseff, após o resultado das eleições de 2010 na capa de três jornais mineiros - Estado de Minas, Hoje em dia e Super Notícia -, de acordo com a abordagem Linguística Sistêmico-Funcional apresentada em Halliday (1994) e Halliday e Matthiessen (2004). Objetivo deste artigo é analisar a representação da presidente Dilma Rousseff após o resultado das eleições de 2010, na primeira página de três jornais mineiros, Estado de Minas, Hoje em Dia e Super Notícia, objetivando compreender quais as operações de seleções e escolhas lexicogramaticais foram suscitadas pelas mídias. Cada jornal se revelou ideológico pois deixou transparecer sua linha editorial por meio das escolhas.

Palavras-chave: Linguística Sistêmico-Funcional, atores sociais, sociedade, contexto.

1. O presente trabalho é parte dos resultados encontrados para a pesquisa intitulada, A representação da presidente Dilma Rousseff: análise discursiva da capa de três jornais mineiros realizada entre janeiro de 2011 e dezembro de 2011, sob a orientação da professora Dr. ${ }^{a}$ Maria Carmen Aires Gomes. Tal pesquisa se vincula ao projeto Sal (Systemics Across Languages).

D.E.L.T.A., 28:Especial, 2012 (515-535) 


\section{Contextualização}

A primeira página de um jornal impresso é um tipo de prática social jornalística que se caracteriza por formas de ações e interações sociais bem específicas. Podemos dizer que se trata de um "gênero discursivo primeira página de jornal", pois sujeitos realizam ações, ou seja, agem discursivamente por meio de manchetes, que mostram a ideia principal da matéria; fotos com legendas, que na maioria das vezes acompanham as manchetes principais; e o resumo (lead) que fornece uma ideia mais completa do conteúdo principal. Dos Santos (2005), discutindo sobre a classificação dos gêneros dos jornais em centrais e periféricos, assume que no "gênero discursivo primeira página de jornal", o cabeçalho e a chamada são considerados centrais-presos; a foto legenda, como central-livre e o anúncio publicitário, periférico, em relação à maior ou menor proximidade da finalidade principal da primeira capa.

Travassos (2010) ressalta que a capa de jornal possui uma variedade de gêneros os quais concorrem para que ela cumpra sua função, que é informar o conteúdo veiculado no jornal e atrair os leitores para a sua compra e leitura. De acordo com esta autora, todos os gêneros presentes na capa estão integrados ao propósito comunicativo geral da mídia jornalística: informar.

No entanto, Gomes (2010), analisando capa de revistas impressas, afirma que o gênero capa de revista tem inicialmente como seu propósito comunicativo vender a revista, captando a atenção do leitor. Busca atrair o púbico, promovendo o que ela tem de melhor a oferecer: a informação. Pode-se assumir então que tanto a capa de revista como a primeira página do jornal tem funções sociocomunicativas semelhantes. A vinculação entre imagem e texto atrai e capta diretamente a atenção do leitor para a compra ou não do jornal/revista. A capa funciona, assim, para a empresa, como uma estratégia de marquetização: informa para vender e vende para informar. Tanto a primeira página do jornal como a capa de revista se caracterizam como um tipo de gênero multimodal capazes de combinar variadas semioses significativas, em sua composição, tais como: cores, imagens gráficas, textos verbais.

A primeira página do jornal se caracteriza como um tipo de vitrine, ou seja, é produzida para não só chamar atenção do leitor, mas para vender o 
jornal: por meio dela o leitor é seduzido a comprar a edição e levá-la para casa. É estruturada de forma a captar a atenção do leitor. Para tanto, se vale de um resumo, ou uma chamada sintética, geralmente formada por grupos nominais, ou orações reduzidas e imagens.

Pode-se dizer que esferas e instituições sociais podem determinar algumas estratégias em função dos recursos linguístico-discursivos empregados, mas não restringi-las. Enquanto determinadas práticas institucionais selecionam estratégias mais flexíveis e abertas, outras restringem ações e interações sociais. Isso implica dizer que, em cada prática social, haverá agentes sociais com capacidade e poder distintos de forma a gerar discursos mais ressonantes capazes de mobilizar um número maior de pessoas (Gomes, 2010). O fato é que cada empresa jornalística usará estratégias discursivas específicas para atrair seus possíveis leitores.

O objetivo deste artigo é analisar a representação da presidente Dilma Rousseff após o resultado das eleições de 2010, na primeira página de três jornais mineiros, Estado de Minas, Hoje em Dia e Super Notícia, objetivando compreender quais as seleções e escolhas linguísticas operadas pelas mídias. Para discutir tais questões, no primeiro momento serão expostos alguns apontamentos sobre os estudos sistêmico-funcionais (Halliday e Matthiessen, 2004), sem seguida são apresentados os Jornais que constituem o material de pesquisa, para enfim passarmos à análise dos dados.

\section{Alguns apontamentos SIStÊMiCO-FunCIONAIS}

A Linguística Sistêmico-Funcional (LSF) compreende a língua como fenômeno sócio-semiótico (Halliday e Hasan, 1985), ou seja, é um produto do processo social, um potencial de significado compartilhado; ao mesmo tempo, uma parte e uma interpretação intersubjetiva² da experiência (Halliday, 1982). Ou seja, é o meio de se refletir sobre as coisas que nos cercam e também nosso modo de agir.

Gouveia (2009, p.22) afirma que o "potencial de significado, escolha, ordem paradigmática e sistema são todos termos relacionados de uma mesma equação." São as dimensões fundamentais do contexto de situação que determinarão

2. Essa noção de língua como um produto da interação social se aproxima das reflexões bakhtinianas sobre a intersubjetividade na língua (1929). 
que certos significados sejam mais prováveis do que outros (cf. Eggins e Martin, 2000). É assim que os componentes da situação ativam certas opções semânticas, levando o falante a fazer escolhas dentre outras prováveis, fazendo com que o uso da língua tenha um caráter probabilístico (Halliday, 1992). Cada escolha realizada influencia e é influenciada pelas demais à sua volta (Thompson, 1996, p. 30), por isso, não se esgotam as possibilidades do sistema linguístico das comunidades. A noção de Contexto de Situação, como aponta Halliday, torna-se fundamental para nossa pesquisa, já que nos propomos a analisar três jornais distintos, que fizeram suas seleções e escolhas de forma a melhor interagirem com seus respectivos leitores. Neste sentido, os jornais interagem com seus leitores, por meio de escolhas específicas, representando e interpretando realidades e experiências de mundo. Como bem pontua Lima-Lopes e Ventura $^{3}$ (2008, p.2), as escolhas "podem não estar em um nível consciente (Thompson, 1994, p. 8): ao escolhermos um processo ou ao fazer de uma entidade o agente, estamos deixando outras opções de lado.", por meio das interferências sociais, culturais, políticas e lingüísticas.

Os estudos sistêmicos se mostram pertinentes pelo fato de o escopo analítico ser o texto, que é observado de duas perspectivas diferentes: a da potencialidade (aquilo que pode significar) e a da instância (o que significa numa situação particular). Cada vez que alguém usa a língua, ativa parte do sistema e, de certa forma, mesmo que, em pequeno grau, muda o sistema. Partindo então do princípio que os estudos sistêmico-funcionais buscam compreender de que forma e porque o homem usa a língua na vida em sociedade, nosso objetivo neste artigo é analisar a forma como três jornais mineiros representaram a vitória de Dilma Rousseff para o cargo de Presidente do Brasil, no dia seguinte à eleição, usando como categoria analítica o significado experiencial realizado por operações de seleção no sistema de transitividade, que se mostram apropriados para tal reflexão e análise crítica dos jornais analisados.

\section{Primeira página do jornal: o QUe eStá dizendo DISCURSIVAMENTE?}

O propósito dessa pesquisa foi analisar a representação da presidente Dilma Rousseff na capa de três jornais mineiros - Estado de Minas, Hoje em

3. Disponível em: http://www2.lael.pucsp.br/direct/DirectPapers55.pdf. Acesso: 10 jan. 2012. 
dia e Super Notícia - no dia seguinte após o resultado das eleições de 2010. A escolha dessas mídias se justifica por serem jornais produzidos no Estado de Minas Gerais, além de ser o estado de origem de Dilma Rousseff. Tal situação pode ter influenciado a forma pela qual as mídias selecionaram os recursos linguístico-discursivos para representar tal evento. Nossa análise foi então delimitada a uma edição de cada jornal. Além disso, cada jornal possui um público alvo específico, afetando, portanto, sua produção gráfica e discursiva. Em linhas gerais, falaremos um pouco de cada uma destas mídias.

Em relação ao jornal Hoje em Dia, de acordo com Carvalho (2007), sua circulação é diária e atende, principalmente, Belo Horizonte e as cidades mineiras consideradas como pólos regionais. Embora apresente um índice de vendas de aproximadamente 1.050 exemplares, em estados, como São Paulo, Rio de Janeiro e Brasília. Segundo o Departamento Comercial do Hoje em Dia, $89 \%$ das vendas do jornal são para assinantes, o que equivale a 30 mil pessoas. Sua tiragem é de 71 mil exemplares por dia, somando Belo Horizonte, as cidades do interior, assinatura e venda avulsa.

O Super Notícia é o terceiro jornal mais vendido no país e possui circulação diária. Assuntos no âmbito da política são pouco abordados, prevalecendo a fórmula "crime-sexo-promoção". Em relação ao perfil dos leitores do Super Notícia, de acordo com Carvalho (2007), a classe social predominante é a C (53\%).

Segundo Dias (2011), o Estado de Minas se constitui como um dos mais relevantes periódicos impressos de Minas Gerais, apesar da redução de venda nos últimos anos. Sua sede é em Belo Horizonte e pertence ao Grupo Diários Associados, que possui 12 jornais, 6 emissoras de televisão, 14 rádios e 10 empresas associadas pelo país. Este Grupo faz parte da sexta maior corporação de empresas de mídia no Brasil. Tem circulação diária. Dias (2011) menciona que há 102.034 mil exemplares nos dias de domingo, sendo que $76 \%$ desta quantia é destinada a assinantes e $24 \%$ à venda avulsa. Nos dias úteis, circulam 71.926 exemplares, sendo que $90 \%$ desta quantia é destinada aos assinantes e $10 \%$ para venda avulsa.

O corpus compreende então três (3) edições, que compõem o material desta pesquisa: o número 25.106 do jornal Estado de Minas, 8.013 do jornal Hoje em Dia e 3.096 do jornal Super Notícia, publicadas no dia primeiro de novembro de 2010, após a vitória democrática e incontestável de Dilma 
Rousseff. Passemos à análise dos textos. Analisaremos aqui o papel dos processos, dos participantes e das circunstâncias na construção textual.

\subsection{Jornal Estado de Minas (EM)}

O jornal traz a seguinte manchete: "Mineira será a primeira presidente". A manchete faz uso do item lexical "mineira", para representar a presidente Dilma Rousseff. Ao representá-la como "mineira", o EM aproxima-a do leitor, criando um vínculo com este, já que Dilma nasceu em Minas Gerais e, de fato, é originalmente mineira. Como se observa na figura abaixo:

\section{MINEIRA SERÁ A PRIMEIRÁ PRESIDENTE}

Figura 1: Jornal Estado de Minas n. 25.106.

O jornal utiliza a forma verbal "será" (no futuro) por meio do qual se estabelece um processo relacional intensivo atributivo entre a portadora "mineira" e o atributo "a primeira presidente", gerando uma atribuição subjetiva, com valor emotivo. Este tipo de processo tem função classificatória porque une duas entidades. Além disso, podemos destacar que o EM categoriza o ator social, ao usar o termo "mineira", o que a diferencia de outras pessoas, pois a inclui no universo daqueles que nasceram em Minas Gerais, estabelecendo vínculos entre Dilma e os leitores do jornal.

Quanto ao sistema de cores, usado na manchete, observamos o uso da cor preta no fraseado "Mineira será a primeira", e a presença da cor vermelha no termo "PRESIDENTE", vinculando o termo presidente ao PT (Partido dos Trabalhadores), cuja cor característica é o vermelho. Observe-se ainda que o termo "presidente" está escrito em uma fonte maior que as demais.

Ainda na primeira página, a figura 2 apresenta a foto legenda, com o texto no quadro. 


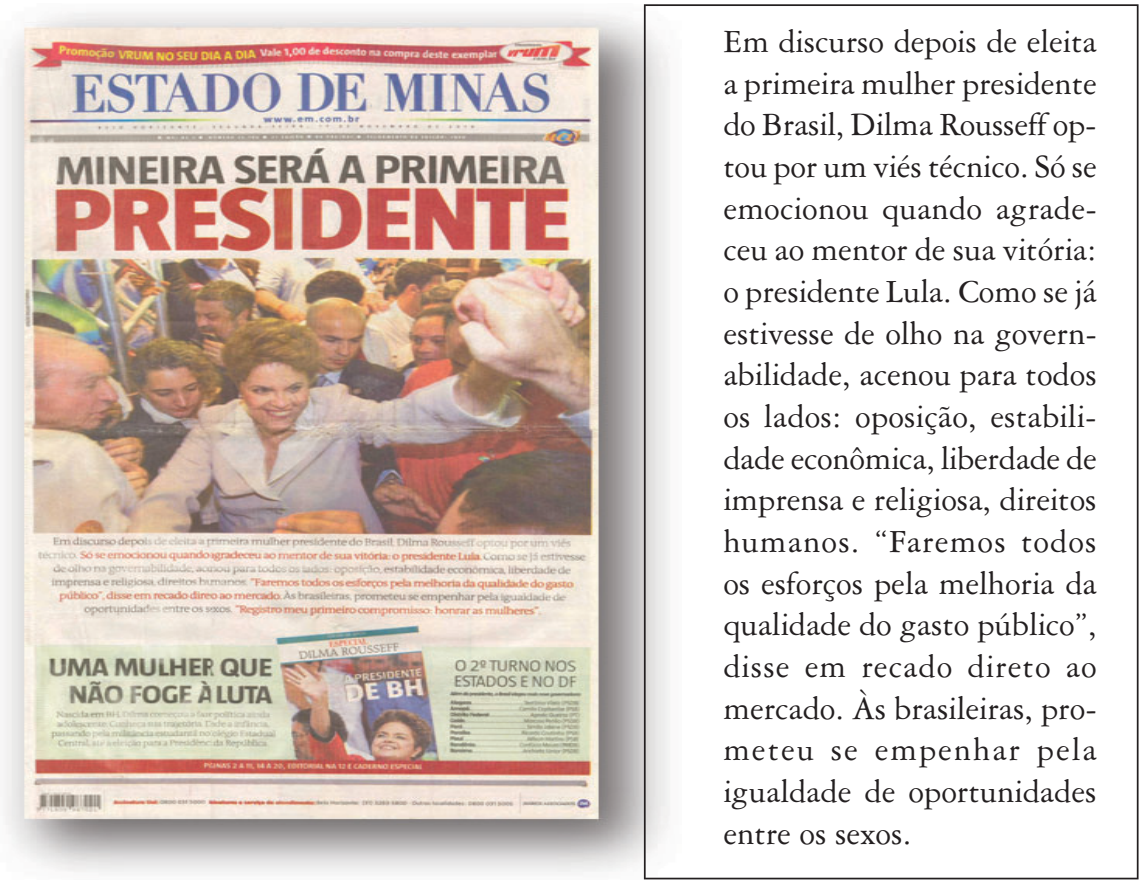

Figura 2: Estado de Minas.

Observe-se que, no texto, Dilma Rousseff é representada por meio de papeis comunicativos bem distintos. Em 1, o termo optou é um processo de cognição, relacionado à decisão e compreensão, tendo Dilma como experienciador, aquela que decide/opta por qual viés produzir o discurso.

1) Em discurso depois de eleita a primeira mulher presidente do Brasil, Dilma Rousseff optou por um viés técnico.

A circunstância de tempo preposta à oração verbal (em discurso depois de eleita a primeira mulher presidente do Brasil) traz a informação "a primeira mulher presidente do Brasil" que é meta do processo material "eleita". A oração mental, que tem Dilma como sensor, ao mesmo tempo falante, é precedida pela circunstância de lugar. Dilma é representada por um tipo de descrição definida que a apresenta como pioneira no cargo.

No excerto abaixo, algumas realizações lexicogramaticais selecionadas para representar o evento midiático são significativas para a análise. $\mathrm{O}$ excerto se inicia com um processo mental desiderativo "estar de olho" - es- 
tivesse de olho na governabilidade que implica semanticamente: "ela desejava/ pretendia/queria a governabilidade". Em seguida é dado à Dilma o papel de agente/atora, gerando uma ação transformadora: acenar para as alianças políticas necessárias para a governabilidade.

2) Como se já estivesse de olho na governabilidade, acenou para todos os lados: oposiz̧ão, estabilidade econômica, liberdade de imprensa e religiosa, direitos humanos.

Pode-se dizer que há uma motivação política aqui: para se fazer um bom governo é necessário acenar para todas as frentes. De experienciadora, Dilma passa a agente/ator de ações concretas (acenar/atrair) que se dirigem a metas específicas (oposição, estabilidade econômica, liberdade de imprensa e religiosa, direitos humanos).

No excerto abaixo, à Dilma é dado inicialmente o papel de experienciadora, para em seguida, representá-la como agente da ação de agradecer a alguém por algo. Dilma é agente da ação de agradecer, e o mentor/ Presidente Lula, recebedor desta ação. A meta é a vitória alcançada por Dilma.

3) Só se emocionou quando agradeceu ao mentor de sua vitória: o presidente Lula.

Ademais, o fraseado "só se emocionou quando agradeceu ao mentor de sua vitória: o presidente Lula" apresenta o termo "só" que, no contexto, indica que o ator social em pauta se emocionou pouco, talvez alinhando-se à imagem já difundida pela mídia de que Dilma é exigente, dura e fria. Também, há a representação de Luiz Inácio Lula da Silva como "o mentor de sua vitória”. Vale ressaltar que mentor é um tipo de "Guia intelectual", ou seja, Luiz Inácio Lula da Silva teria proporcionado a vitória para a presidente Dilma Rousseff devido às suas idéias. Tal construção discursiva reforça a imagem construída de Lula durante a campanha eleitoral e o fato de que Dilma seria eleita em função da popularidade do ex-presidente Lula. Observe ainda a topicalização do nome do ex-presidente Lula, atribuindo a ele um papel central na informação, pois coloca o termo em evidência dando-lhe destaque e valorização.

Em seguida, por meio de um discurso direto, o jornal Estado de Minas reporta o dizer do ator social "(...) Faremos todos os esforços pela melhoria da qualidade do gasto público (...)". Percebemos que esta fala é introduzida por um verbo de ação material "faremos" em que a meta trata-se da informa- 
ção "todos os esforços pela melhoria da qualidade do gasto público". Além disso, o foco verbal está no plural, indicando que não só a presidente Dilma Rousseff, mas toda a sua equipe irá fazer esforços. Também, ela e sua equipe são participantes de ações concretas, dinâmicas.

No trecho “(...) Às brasileiras, prometeu se empenhar pela igualdade de oportunidades entre os sexos (...)", o jornal coloca Dilma como dizente do processo prometer, que é um verbo de troca dialógica, pois exige a presença de dois participantes: dizente e alvo:

\begin{tabular}{|l|l|l|}
\hline Às brasileiras & Prometeu & $\begin{array}{l}\text { se empenhar pela igualdade de oportunidades } \\
\text { entre os sexos }\end{array}$ \\
\hline Participante: alvo & Processo: verbal & Verbiagem \\
\hline
\end{tabular}

Para dar credibilidade à promessa feita às brasileiras, o Jornal ressalta ainda o discurso direto da presidente Dilma Rousseff "(...) Registro o meu primeiro compromisso: honrar as mulberes.":

\begin{tabular}{|l|l|l|}
\hline Registro & o meu primeiro compromisso & $\begin{array}{l}\text { honrar as mulheres } \\
\text { (que é honrar as mulheres) }\end{array}$ \\
\hline Processo: verbal & Participante: verbiagem & oração projetada \\
\hline
\end{tabular}

Vale destacar, no fraseado, o uso do verbo "registrar" no sentido de assinalar, firmar oficialmente um compromisso/promessa; diferente do verbo prometer, não pressupõe necessariamente um participante a quem se dirija a mensagem. Na oração projetada - honrar as mulberes -, o processo material "honrar", no sentido de respeitar, tem como meta: as mulheres. O jornal EM, ao usar o discurso direto, legitima a fala da Presidente, deixando claro que as questões que cercam as mulheres terão prioridade em seu governo.

Provavelmente o jornal, ao colocar os trechos em vermelho, pretendeu dar destaque às informações neles expressas, reforçando a cor da bandeira do partido, que é uma cor associada ao desafio, simbolizando também o sangue vertido numa luta histórica.

O texto abaixo se localiza na parte inferior da primeira página e tem como título: "Uma mulher que não foge à luta"; neste fraseado, há uma referência genérica do participante dinâmico, que realiza o processo mate- 
rial "foge". A partir do trecho supracitado, podemos observar que o Jornal retrata a presidente Dilma Rousseff como uma combatente, uma lutadora, já que associa o nome dela à ação de lutar, dizendo que ela "não foge à luta”; a construção da metáfora da guerra é muito recorrente no discurso político midiatizado (Barbara e Gomes, 2010).

O texto que acompanha o título acima traz algumas significações experienciais bem interessantes:

4) Nascida em BH, Dilma comegou a fazer política ainda adolescente. Conbeşa sua trajetória. Desde a infância, passando pela militância estudantil no Colégio Estadual Central, até a eleição para a Presidência da República.

Na informação "Nascida em BH, Dilma começou a fazer política ainda adolescente", observa-se a circunstância "Nascida em BH", em posição temática. Ao fazer isso, o Jornal aproxima a presidente do seu público, também mineiro, criando uma cumplicidade entre eles. Ainda, individualiza a participante "Dilma" especificando-a por meio da nomeação informal. Além disso, Dilma torna-se agente/atora do processo material "começou a fazer", tendo como meta "política", em uma circunstância bem específica: ainda adolescente. O uso do léxico "ainda", indicando que a Presidenta entrou para a carreira política jovem, é reforçado ao mostrar aos leitores a trajetória dela (Desde a infância, passando pela militância estudantil no Colégio Estadual Central, até a eleição para a Presidência da República).

Na capa da edição especial do Estado de Minas exposta na parte inferior da primeira página, há outra representação interessante: "A presidente de BH". A oração relacional possessiva "presidente de BH" faz referência ao fato de a Dilma ter nascido em $\mathrm{BH}$, relacionando-a a este estado, aproximando-a dos mineiros, criando uma identificação de grupo. O jornal representa Dilma pela sua função e titulação: presidente.

Quanto à imagem representada na capa do jornal Estado de Minas, podemos dizer que há duas. A primeira mostra a parte superior corporal da presidente, pois focaliza o abdômen dela. Dilma Rousseff está sorrindo, demonstrando satisfação e não olha diretamente para o leitor do jornal, mas para o lado esquerdo da página; do olhar da presidente eleita sai um vetor em direção ao braço dela erguido, acenando para o povo (Kress e van Leeuwen, 1996). 


\subsection{Jornal Hoje em Dia}

O jornal Hoje em Dia traz na manchete uma construção nominal: "A Era Dilma". Pode-se dizer que tal construção nos remete à "Era Vargas", período populista vivido pela sociedade brasileira. Ao fazer tal escolha, o Jornal cria uma relação entre o governo de Dilma Rousseff e o de Getúlio Vargas. Além disso, a palavra "Era" significa "período geralmente longo, que principia com um fato marcante ou que dá origem a uma nova ordem de coisas" ${ }^{4}$.

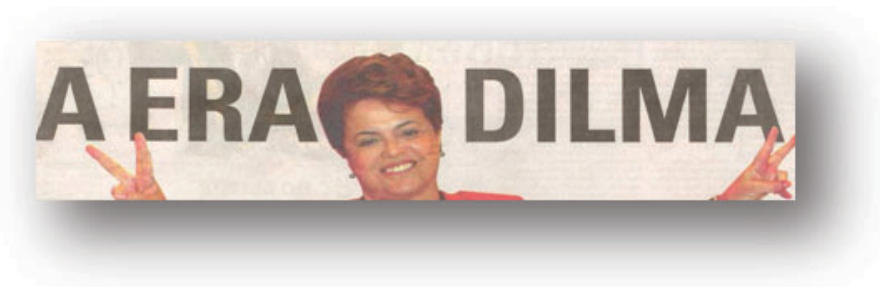

Figura 3: Jornal Hoje em Dia.

O jornal escolhe a nomeação informal para representar o ator social em questão: Dilma, criando uma relação de cumplicidade e aproximação entre o jornal, leitores e a Presidente. Vale destacar ainda que, entre as informações "A era" e "Dilma", há uma manipulação gráfica de forma a destacar o rosto da atora social. Ou seja, imagem e texto reforçam a construção identitária proposta pelo jornal.

Passemos inicialmente à análise do texto que acompanha a foto da primeira página do jornal, localizado à direita da página, na parte superior. Neste, o ator social é representado como "A belo-horizontina Dilma Rousseff". Nesta construção, além de individualizar a atora social, a nomeia de maneira semi-formal, classificando-a pela origem.

4. Disponível em: www.acervo.com.br/novaera/significadoeorigem. Acesso em: 16 nov. 2011. 


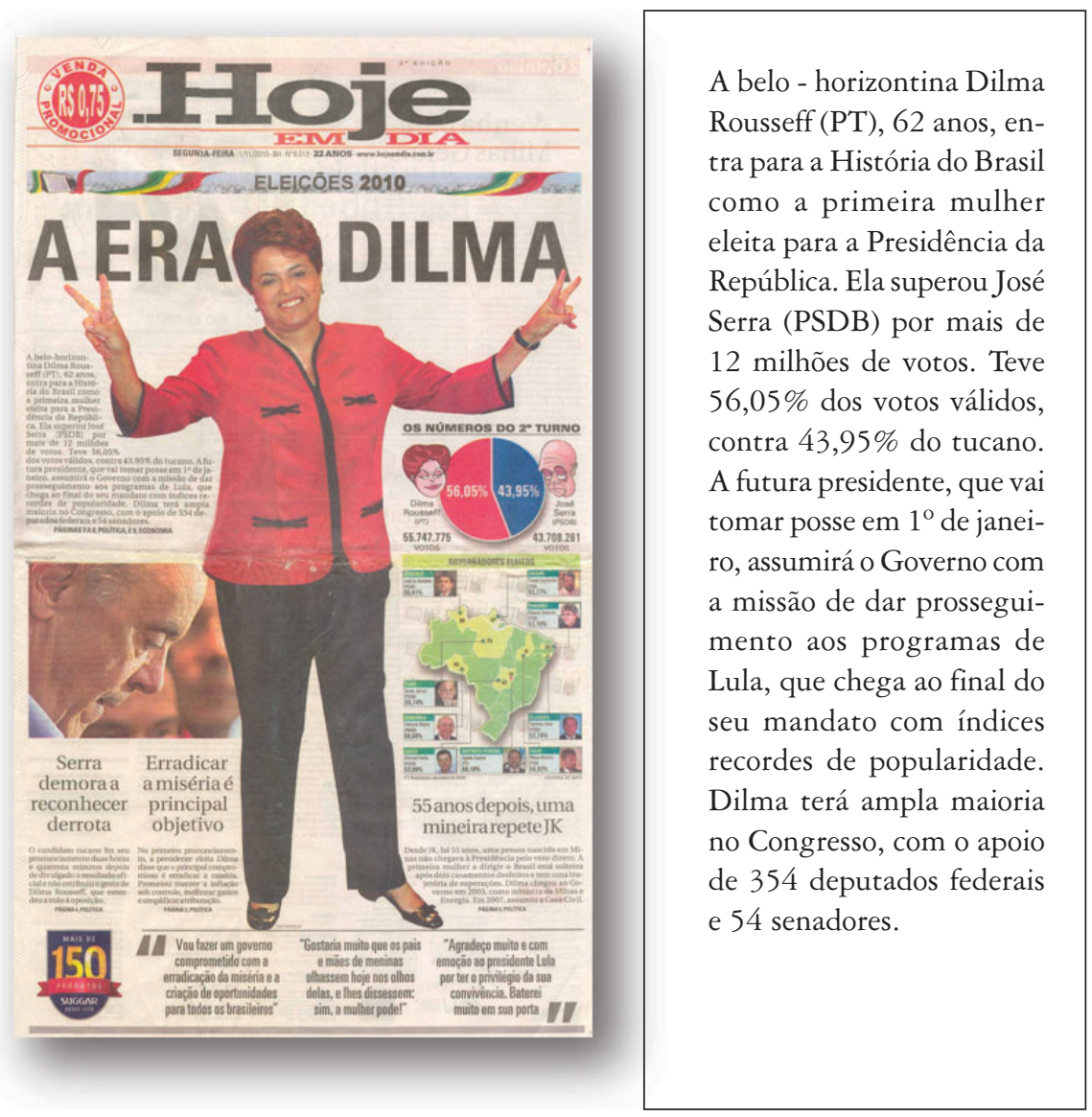

Figura 4: Jornal Hoje em Dia.

No fraseado "A belo-horizontina Dilma Rousseff (PT), 62 anos, entra para a história do Brasil como a primeira mulher eleita para a Presidência da República", o ator social Dilma Rousseff assume um papel ativo em relação à atividade material "entra". Há a indicação de dados pessoais da presidente, tais como, o partido ao qual ela se filia (PT) e a idade (62 anos). Após o processo, há dois elementos circunstancializadores: um espacial, "para a história do Brasil", e outro, de modo: como a primeira mulher eleita (...)". Nesta circunstância de modo, há um atributo, uma qualidade: "a primeira".

Vale destacar que neste fraseado, a ação material "eleita" tem como meta: "para a presidência da República". Além disso, podemos ressaltar 
que tanto a representação da presidente, quanto a meta são introduzidos pelo artigo definido "a” que, além de definir, realça e valoriza o léxico que o acompanha.

No excerto (5), "ela” é o agente/atora do processo material “superou”, como se observa abaixo:

5) "(...) Ela superou José Serra (PSDB) por mais de 12 milhões de votos”.

O circunstancializador "por mais de" contextualiza a ideia de que a presidente obteve mais do que 12 milhões de votos, ou seja, esta quantificação mostra que a superação da presidente Dilma aconteceu em grande proporção, dando maior legitimidade e credibilidade à eleição.

Em seguida, o jornal se refere à Dilma como "a futura presidente", representada pelo processo de ativação, pois assume uma função dinâmica em relação aos processos materiais "vai tomar" e "assumirá", como se observa no excerto abaixo:

6) A futura presidente, que vai tomar posse em $1^{\circ}$ de janeiro, assumirá o Governo com a missão de dar prosseguimento aos programas de Lula, que chega ao final do seu mandato com índices recordes de popularidade.

No trecho circunstancializador “(...) com a missão de dar prosseguimento aos programas de Lula (...)", podemos evidenciar que a informação "missão de dar prosseguimento" pressupõe-se que algo já estava sendo feito e continuará a ser realizado. Em "índices recordes de popularidade", nota-se o uso do léxico "recorde" que significa ultrapassar algo já estabelecido em condições idênticas, ou seja, o jornal Hoje em Dia evidencia que a atuação de Luiz Inácio Lula da Silva foi a que mais agradou à população, por isso, dizem, ser ele o mentor da Dilma nesta missão a ser realizada.

Em "Dilma terá ampla maioria no Congresso, com o apoio de 354 deputados federais e 54 senadores" percebemos que o ator social faz parte de um processo relacional de posse: "terá", tornando-se a possuidora de "ampla maioria". A atora social é individualizada por meio da nomeação "Dilma", demonstrando certa aproximação do tratamento que este jornal dá a este ator social com o público a que se destina.

Na parte inferior da capa do jornal, há três chamadas às quais também se referem ao ator social. Na primeira, destaca-se o seguinte trecho: "O 
candidato tucano (...) não retribuiu o gesto de Dilma Rousseff, que estendeu a mão à oposição.” Podemos destacar que o jornal classifica o José Serra - o candidato tucano - como participante agente da ação material negativa de “não retribuir o gesto”, ou seja, ao fazer isso, evidencia que José Serra não teve a mesma consideração que a presidente teve em relação à oposição. Ou seja: constrói uma identidade positiva para a presidente eleita.

7) Serra demora a reconhecer derrota. O candidato tucano fez seu pronunciamento duas horas e quarenta minutos depois de divulgado o resultado oficial e não retribuiu o gesto de Dilma Rousseff, que estendeu a mão à oposição.

No excerto abaixo, observe que a circunstância na posição temática, "no primeiro pronunciamento", legitima a fala da atora social. Dilma aparece como dizente (a presidente eleita Dilma) da oração projetada: "o principal compromisso é erradicar a miséria”, como se observa abaixo:

8) Erradicar a miséria é o principal objetivo. No primeiro pronunciamento, a presidente eleita Dilma disse que o principal compromisso é erradicar a miséria. Prometeu manter a inflação sob controle, melhorar gastos e simplificar a tributação.

\begin{tabular}{|l|l|l|l|l|l|}
\hline $\begin{array}{l}\text { No primeiro } \\
\text { pronuncia- } \\
\text { mento }\end{array}$ & $\begin{array}{l}\text { A presidente } \\
\text { eleita dilma }\end{array}$ & disse que & $\begin{array}{l}\text { O principal } \\
\text { compromisso }\end{array}$ & é & erradicar a fome \\
\hline Circunstância & $\begin{array}{l}\text { Participante } \\
\text { dizente }\end{array}$ & $\begin{array}{l}\text { Processo } \\
\text { verbal }\end{array}$ & $\begin{array}{l}\text { Oração proje- } \\
\text { tada }\end{array}$ & $\begin{array}{l}\text { Processo } \\
\text { relacional }\end{array}$ & $\begin{array}{l}\text { Identificador } \\
\text { Processo mate- } \\
\text { rial: erradicar } \\
\text { Meta: a fome }\end{array}$ \\
\hline
\end{tabular}

A figura acima mostra ainda que Dilma (de forma elíptica) é dizente do processo "prometer", verbo que pressupõe traços de troca dialógica, exigindo a presença de participantes. A verbiagam apresenta o teor da promessa: manter a inflação sob controle, melhorar gastos e simplificar a tributação.

No excerto 9, observamos algumas questões em relação ao uso dos elementos circunstanciais, uma vez que estes definem os contextos. Para Halliday (1994), as circunstâncias podem introduzir argumentos de forma indireta.

9) Desde JK, há 55 anos, uma pessoa nascida em Minas não chegava à Presidência pelo voto direto. A primeira mulher a dirigir o Brasil está solteira após dois casamentos desfeitos e tem uma trajetória de superaçôes. Dilma chegou ao Governo em 2003, como ministra de Minas e Energia. Em 2007, assumiu a Casa Civil. 
Observe que o jornal inicia o texto, com dois elementos circunstanciais temporais "desde $\mathrm{JK}$, há 55 anos" em posição temática e, ao fazer isso, pode de alguma forma criar um vínculo entre os políticos: JK e Dilma, ambos nascidos em Minas gerais, criando uma aproximação/cumplicidade com o cidadão mineiro. Destaca-se o participante (uma pessoa nascida em Minas) do processo material (não chegava) e da meta (à Presidência) por meio "do voto direto".

Ainda no excerto 9, vale destacar que, na oração seguinte, o tema muda, colocando em proeminência a informação "a primeira mulher a dirigir o Brasil" que é um portador de um processo atributivo intensivo "está solteira", além do elemento circunstancial "após dois casamentos desfeitos". Observe que tal tópico enfatiza uma questão puramente pessoal e não política, como a informação dada na oração anterior. O jornal aponta ainda outra característica da candidata eleita: "tem uma trajetória de superações", em que a coloca como portadora de ações e práticas positivas.

Em relação às imagens expostas na capa, a que está em posição de destaque abrange todo o corpo da presidente Dilma Rousseff, que sorri, olhando para frente, na direção do leitor do jornal e com os braços erguidos fazendo o sinal de vitória com as duas mãos. Ela está usando uma blusa vermelha, que é a cor representativa do PT e uma calça preta. No lado direito da capa e em uma parte mais inferior, há uma imagem que se opõe a de Dilma sorridente: José Serra de cabeça baixa e com uma expressão triste, indicativa de derrota. Ao lado desta imagem, há uma representação em porcentagem dos votos obtidos pelos candidatos Dilma Rousseff e José Serra no segundo turno das eleições. Nota-se que junto a esta representação há uma imagem caricatural do rosto dos dois políticos. Dilma sorri, enquanto José Serra está com a face triste. Observe que há um alinhamento informativo entre os textos verbais e visuais.

Passemos à análise do último jornal.

\subsection{Jornal Super Notícia}

A capa deste tablóide traz a seguinte manchete: "Brasil elege a $1^{\mathrm{a}}$ mulher presidente". Percebemos que o jornal faz uso do termo "Brasil" como ator e agente, já que a ele é atribuída função dinâmica em relação ao evento "elege", que, por sua vez, trata-se de um processo material. 


\section{BRASIL ELEGE A 19 MULHER PRESIDENIE}

Figura 5: Jornal Super Notícias.

O léxico "Brasil" é representado através da categoria da assimilação por coletivização (van Leeuwen, 1997), já que o termo denota um grupo de pessoas, os brasileiros. Além disso, através desta realização, o jornal legitima a eleição, demonstrando que foi o país (Brasil) que elegeu a presidente Dilma Rousseff.

O fraseado "a $1^{\mathrm{a}}$ mulher presidente" é uma meta do processo material (elege), realizada por meio da descrição definida, que pressupõe o fato de o Brasil não ter tido em sua história ainda uma presidente mulher. Aliás, não é uma mulher, mas sim "a” primeira mulher.

A cor vermelha usada, como pano de fundo, na manchete, também é muito significativa, pois se trata da cor representativa do PT ao qual Dilma Rousseff é filiada.

Primeiramente, será exposta a primeira capa do jornal Super Noticia e, posteriormente, será realizada a análise descritivo-interpretativa.

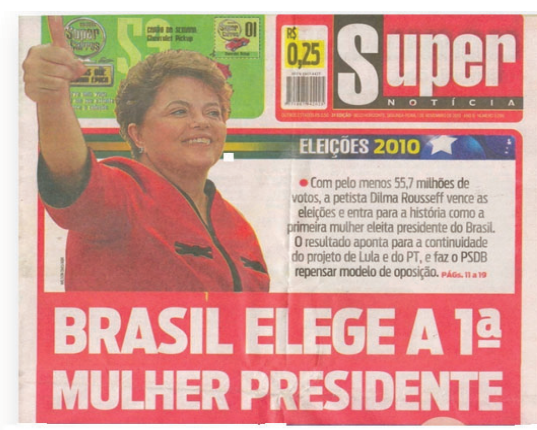

Com pelo menos 55,7 milhões de votos, a petista Dilma Rousseff vence as eleições e entra para a história como a primeira mulher eleita presidente do Brasil. O resultado aponta para a continuidade do projeto de Lula e do PT, e faz o PSDB repensar modelo de oposição.

Figura 6: Jornal Super Notícias. 
O primeiro texto a ser analisado da capa do jornal Super Notícia é o que se encontra ao lado da imagem da presidente Dilma. No fraseado "Com pelo menos 55,7 milhões de votos, a petista Dilma Rousseff vence as eleições e entra para a história como a primeira mulher eleita presidente do Brasil.", o elemento circunstancial "Com pelo menos 55,7 milhões de votos" foi colocado em proeminência, em posição temática, dando destaque à quantidade de votos obtidos pela presidente Dilma Rousseff, na eleição. Além disso, há a circunstância "pelo menos" que confere a ideia de que a presidente teve, no mínimo, 55, 7 milhões de votos, ou seja, a quantidade de votos poderia ser ainda maior. O dado numérico 55,7 milhões realiza uma referência específica, dando uma precisão maior à informação que está sendo veiculada, sugerindo ao leitor exatidão, legitimidade e credibilidade ao resultado da eleição.

Nesta oração o ator social é representado pelo atributo "a petista Dilma Rousseff". Podemos ressaltar que esta representação confere a este ator social uma agência já que realiza ações concretas e dinâmicas (vence e entra).

Ainda em relação a este fraseado, ressaltamos o uso do processo material "vence" seguido da meta "as eleições". Já o verbo "entra" é seguido de uma circunstância espacial "para a história".

No excerto 10, a metáfora gramatical "resultado" realiza duas ações materiais: aponta e faz, em que a informação "para a continuidade do projeto de Lula e do PT" é a meta do processo "aponta".

10) O resultado aponta para a continuidade do projeto de Lula e do PT, e faz o PSDB repensar modelo de oposição.

Já a mensagem "o PSDB repensar modelo de oposição" é a verbiagem. No entanto, vale ressaltar que é o resultado que faz o PSDB repensar processo mental - refletir sobre o fenômeno, que é "modelo de oposição" ao governo. Este fraseado evidencia a construção ideológica, pois a palavra "continuidade" pressupõe que algo já começou, ou seja, Lula e PT já iniciaram um projeto e caberá à Dilma continuá-lo. É interessante notar que o léxico Lula associado ao termo "projeto" realiza, no excerto, uma construção lingüística de posse. Tal escolha sugere que o projeto não é do Partido, mas do ex-presidente Lula.

A imagem expressa na capa focaliza a parte superior da presidente Dilma Rousseff, plano pessoal. $\mathrm{Na}$ face da presidente há um sorriso, que 
demonstra satisfação. O Olhar não se direciona ao leitor do jornal, não cria esta demanda ou possível alinhamento, estão direcionados para o canto esquerdo da página, para um possível fenômeno, talvez o povo (Kress e van Leeuwen, 1996). O braço está erguido e, por meio dele, a presidente faz um sinal, popularmente conhecido como "jóia", o qual cria uma proximidade entre ela e o povo. A cor da roupa da presidente é vermelha.

A figura abaixo traz o último texto relativo às eleições exposto na primeira página. Neste, o enfoque não está na figura de Dilma Rousseff, mas sim em José Serra.
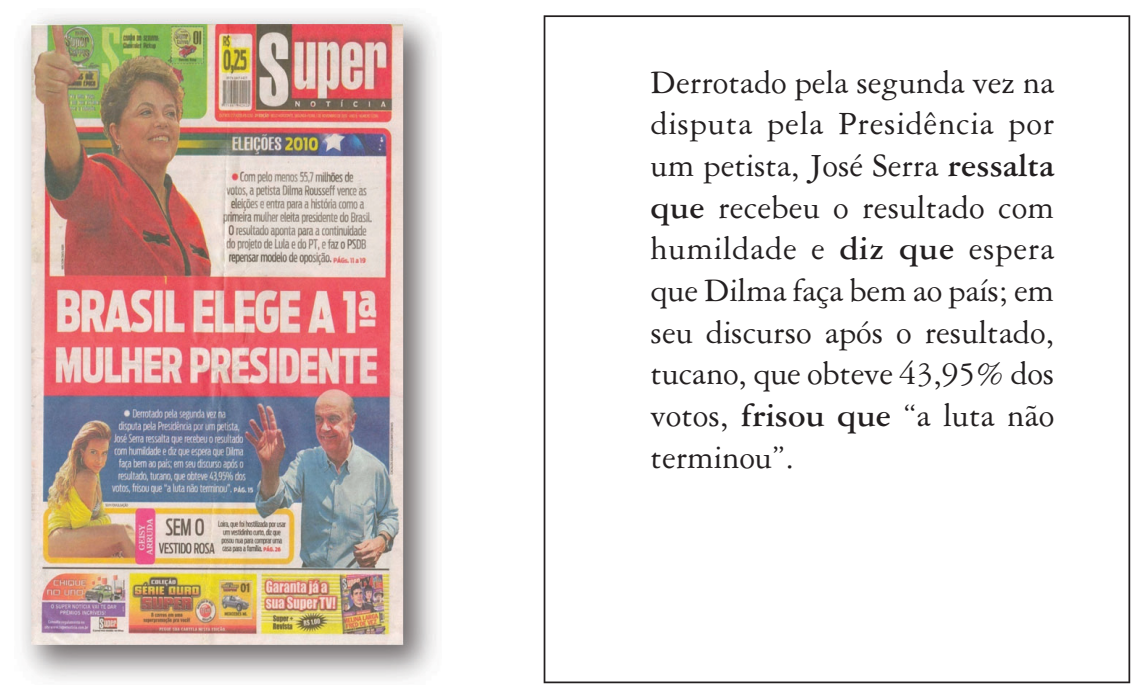

Figura 7: Jornal Super Notícias.

O processo material "derrotado" está em posição temática, em proeminência, dando destaque ao evento: a derrota por um petista, reforçado ainda pelo elemento circunstancial "pela segunda vez na disputa pela Presidência".

O jornal, por meio de orações verbais projetadas, usa verbos que não apresentam traços de troca dialógica entre os participantes, não realizam uma construção negociada. Ao fazer isto, dá ao José Serra apenas a função de dizente dos verbos: ressalta, diz e frisou. Há três orações projetadas que evidenciam a carga ideológica construída pelo jornal. A primeira oração coloca José Serra como beneficiário da ação de receber algo (o resultado) 
de maneira circunstancial (com humildade). Na segunda projeção, Serra se coloca como um experienciador da ação do fenômeno Dilma. Ironicamente o jornal reproduz o discurso de Serra de que o atual Governo possa não ser bom para o Brasil. A terceira oração projetada destaca o fato de o José Serra usar um mote que é característico dos partidos de esquerda: a luta não terminou, reforçando o discurso político da guerra, em que aliados se confrontam com seus adversários.

\section{Algumas considerações finais}

A partir da análise lexicogramatical, a figura de Dilma Rousseff construída pelos jornais é a de uma participante que ora age de forma dinâmica, ora experiencia emoções, sentimentos e desejos. A explícita menção ao fato da Presidente ser originalmente de Minas Gerais, mais especificamente de Belo Horizonte, cria entre jornal e leitores certa cumplicidade e aproximação com a atual Chefe de Estado.

As escolhas lexicogramaticais distintas em torno da representação da Presidenta demonstram que, em termos de prática textual e discursiva, foram seleções operacionalizadas para atender certos objetivos sociocomunicativos e políticos das mídias analisadas.

Nos jornais analisados, Dilma Rousseff foi representada de forma nomeada, personalizada (Dilma, Dilma Rousseff), mas também de forma categorizada e classificatória: mineira, petista. Vale destacar que as informações "primeira presidente" e "primeira mulher eleita" são sistematicamente usadas pelos jornais e são de fato atribuições importantes que reforçam o contexto e o resultado histórico da eleição de 2010. Houve ainda certa recorrência do uso de circunstâncias, na posição temática, chamando atenção para o referido resultado histórico.

No que se refere ao investimento ideológico dos jornais, cabe ressaltar que o jornal Hoje em dia construiu um discurso com um tom mais apelativo e manipulativo ao produzir o título "A era Dilma", resgatando politicamente o interdiscurso "Era Vargas".

Enfim, os resultados reforçam o fato de que os eventos instanciados pela mídia fazem parte de uma operação complexa de seleção, que é orientada 
por interesses econômicos e sociopolíticos, gerando assim uma construção social da notícia.

Recebido em setembro de 2011

Aprovado em novembro de 2011

E-mail: mariacarmengomes@hotmail.com

\section{REFERÊNCIAS BIBLIOGRÁFICAS}

Barbara, Leila \& Gomes, Maria Carmen Aires. 2010. A representação de Dilma Rousseff pela mídia impressa brasileira: analisando os processos verbais. Letras (UFSM), v. 20, p. 67-92.

Carvalho, Flaviane. 2007. Os significados composicionais e a formação de subjetividades na primeira página de jornais mineiros: um estudo de caso à luz da gramática do design visual. Dissertação de Mestrado. FALE/UFMG, Belo Horizonte.

DA SILVA, Margareth. 2002. A representação dos atores sociais no discurso político eleitoral. Dissertação de Mestrado. UCP, Pelotas.

Dias, Luciene. 2011. A seção ciência no Estado de Minas e na Folba de S. Paulo: Um estudo comparativo sob a ótica da análise do discurso da divulgação científica e da gramática do design visual. Dissertação de Mestrado. UFV: Viçosa.

DOs Santos, Glauciane. 2005. Análise do gênero discursivo "primeira página de jornal": um estudo de caso dos jornais da cidade de Ponte Nova. Monografia. DLA/UFV. Viçosa.

EGGINs, Suzanne; MARTIN, Jean. 1997. Genres and registers of discourse. In: VAN DijK, T. (ed.). Discourse as structure and process - discourse studies: a multidisciplinary introduction. London: Thousand Oaks; New Delhi: Sage Publications.

Estado de Minas. 2011. Belo Horizonte, 1 de novembro, p.1.

Fowler, Roger. 1991. Language in the news: discourse and ideology in the press. London ad New York.

Ghio, Elza.; Fernandez, M.D. 2005. Manual de Linguistica Sitemico Funcional. El enfoque de M.A.K. Halliday y Hasan. Aplicaciones a la lengua espanola. 1ed. Santa Fé: Universidad Nacional del Litoral.

Gomes, Maria Carmen Aires. 2010. Ação social midiatizada: analisando a recontextualização de um evento social. Ling. (dis)curso (Impr.) vol.1 0 no.2 Tubarão Aug. 
Gouveia, Carlos. 2009. Texto e Gramática: uma introdução à Lingüística Sistêmico-Funcional. Matraga. Rio de Janeiro, v.16, n.24, jan./jun.

HallidAY, M. A. K. 1978. Language as social semiotic: the social interpretation of language and meaning. London: Edward Arnold.

. 1982. El lenguaje como semiotica social: la interpretacion social del lenguaje y del significado. Tradução. Jorge Ferreiro Santana. México: Fondo de Cultura Economica.

. 1985. An introduction to functional grammar. London: Edward Arnold.

. 1994. An introduction to functional grammar. 2nd ed. London: Edward Arnold.

Halliday, M. A. K. 2004. An introduction to functional grammar. 3rd ed. Revised by Christian M. I. M. Mathiessen. London: Arnold Edition. ; Hasan, Ruquia. 1989. Language, context, and text: aspects of language in a social-semiotic perspective. Oxford: Oxford University Press.

HASAN, Ruquia. Language and society in a systemic functional perspective. In: Hasan, Ruquia; Matthiessen, Christian; Webster, J. 2005. Continuing discourse on language. London: Equinox Publishing Ltd.

Hoje em Dia. 2011. Belo Horizonte, 1 de novembro. p.1.

Kress, Gunther.; van LeEuwen, Theo van. 1996. Reading images: the grammar of design visual. London: Routledge.

Super Notícia. 2011. Belo Horizonte, 1 de novembro. p.1.

Travassos, Tarcísia. 2010. A transformação histórica do gênero capa de jornal. Tese de Doutorado em Linguística. UFPE: Recife.

van Leeuwen, Theo. A representação dos atores sociais. In: Pedro, Emília Ribeiro. 1997. Análise Crítica do Discurso. Lisboa: Editorial Caminho. 